\title{
Usefulness of combined androgen blockade therapy with gonadotropin- releasing hormone antagonist for bone metastatic prostate cancer with pretreatment prostate-specific antigen level $\geq 50 \mathrm{ng} / \mathrm{mL}$
}

\author{
Takeshi Kashiwabara* ${ }^{*}$ and Sayo Suda
}

\begin{abstract}
Background: This study was performed to examine the usefulness of combined androgen blockade (CAB) therapy with a gonadotropin-releasing hormone $(\mathrm{GnRH})$ antagonist (CAB-antagonist therapy), instead of $\mathrm{CAB}$ therapy with $\mathrm{GnRH}$ agonist (CAB-agonist therapy) against very high-risk prostate cancer (Pca).

Methods: We retrospectively studied 84 Pca patients with pretreatment prostate-specific antigen (PSA) level $\geq 50 \mathrm{ng} / \mathrm{mL}$, who were pathologically diagnosed between January 2007 and December 2016. GnRH antagonist was administered to 34 patients and $\mathrm{GnRH}$ agonist was administered to 50 patients. All patients received concurrent antiandrogen treatment.

The primary end point was PSA progression-free survival (PSA-PFS).

Results: PSA-PFS was significantly longer for the CAB-antagonist group compared to the CAB-agonist group (log-rank test, $P<0.01$ ) in Pca patients with more than six bone metastases (the extent of disease [EOD] grade 2-4). On multivariate analysis, CAB-antagonist therapy was shown to be a possible prognostic factor for PSA-PFS (adjusted hazard ratio: 0.41, 95\% confidence interval: $0.16-0.90, P=0.03$ ).
\end{abstract}

Conclusions: CAB-antagonist therapy may be a useful option in bone metastatic Pca patients with EOD grade 2-4.

Keywords: Bone metastasis, Combined androgen blockade, Gonadotropin-releasing hormone receptor antagonist, Prostate cancer

\section{Background}

Japan had 92,600 patients with prostate cancer (Pca) in 2016, making it the most common form of cancer among men in the country, and both the incidence and number of deaths from Pca are increasing. The 5- and 10-year survival rates of non-metastatic Pca are close to $100 \%$. However, metastatic Pca shows 5- and 10-year survival rates of 62 and $49 \%$, respectively, and many patients that died of Pca had advanced cancer at the time

\footnotetext{
* Correspondence: kashiwabara.takeshi@sakuhp.or.jp Department of Urology, Saku Central Hospital, 197 Usuda, Saku, Nagano 384-0393, Japan
}

of diagnosis [1]. In 2014, $14 \%$ of patients were found to have suffered from metastatic Pca in Japan. Japan's Clinical Practice Guidelines recommended combined androgen blockade $(\mathrm{CAB})$ as the standard therapy for metastatic Pca. CAB therapy, which involves concurrent use of a gonadotropin-releasing hormone $(\mathrm{GnRH})$ agonist and non-steroidal antiandrogen (CAB-agonist), is more effective than androgen deprivation therapy (ADT) alone and is recommended as the standard treatment for high-risk Pca in Japan. Patients on primary ADT in Japan were reported to have an adjusted prostate cancer-specific mortality rate less than half those in the

(c) The Author(s). 2018 Open Access This article is distributed under the terms of the Creative Commons Attribution 4.0 International License (http://creativecommons.org/licenses/by/4.0/), which permits unrestricted use, distribution, and reproduction in any medium, provided you give appropriate credit to the original author(s) and the source, provide a link to the Creative Commons license, and indicate if changes were made. The Creative Commons Public Domain Dedication waiver (http://creativecommons.org/publicdomain/zero/1.0/) applies to the data made available in this article, unless otherwise stated. 
USA. The adverse event of $C A B$ is tolerable and the cost of $C A B$ is acceptable for patients. Although these guidelines take into account that there is no clear evidence of the efficacy of $\mathrm{CAB}$ in metastatic Pca, CAB-agonist therapy is widely used in treatment of advanced or metastatic Pca throughout Japan [2]. However, it remains difficult to improve the prognosis of metastatic Pca, and an improved therapeutic modality is required.

Recently, next-generation $C A B$ therapy, abiraterone with ADT, was reported to significantly prolong overall survival (OS) and progression-free survival (PFS) in metastatic and hormone-sensitive Pca (HSPC) compared to ADT alone. Most of the metastatic Pca patients in these studies received GnRH agonist as ADT [3, 4]. Unlike GnRH agonists, the GnRH antagonist, degarelix, neither induces a transient rise in testosterone nor aggravates the symptoms. Antiandrogen was administered concurrently in $83 \%$ of patients treated with degarelix in Japan. It is of interest to determine whether there are differences in efficacy between $\mathrm{GnRH}$ antagonist and $\mathrm{GnRH}$ agonist in $\mathrm{CAB}$ therapy.

Sixty-five percent of Pca patients with prostate-specific antigen (PSA) level $>50 \mathrm{ng} / \mathrm{mL}$ have metastatic disease, and optimal management for these patients is controversial [5]. Patients with PSA level $>50 \mathrm{ng} / \mathrm{mL}$ were reported to have higher risk of PSA recurrence than those with PSA level $20-50 \mathrm{ng} / \mathrm{mL}$ [6]. The baseline serum alkaline phosphatase (ALP) in patients with PSA level $>50 \mathrm{ng} / \mathrm{mL}$ is four times higher than in those with PSA level $<50 \mathrm{ng} / \mathrm{mL}$, and high serum ALP indicated metastatic disease in patients with PSA level $>50 \mathrm{ng} / \mathrm{mL}$ [7]. PSA control after treatment was reported to be associated with improved OS. GnRH antagonist monotherapy was shown to be associated with improved PSA-PFS compared with $\mathrm{CAB}$-agonist therapy [8]. Patients with PSA level $\geq 50 \mathrm{ng} / \mathrm{mL}$ were suitable for inclusion in our retrospective patient cohort study. Here, we compared the therapeutic effects of $\mathrm{CAB}$ using concurrent $\mathrm{GnRH}$ antagonist (CAB-antagonist) and $\mathrm{CAB}$-agonist therapy in treatment of high-risk Pca with PSA level $\geq 50 \mathrm{ng} / \mathrm{mL}$.

\section{Methods}

We identified 103 patients with a pathological diagnosis of Pca with PSA level $\geq 50 \mathrm{ng} / \mathrm{mL}$ at our hospital between January 2007 and December 2016 (Fig. 1). All cases were followed up for more than 12 weeks. GnRH antagonist (degarelix) or GnRH agonist (leuprorelin in 13 cases and goserelin in 37 cases) was administered as ADT. Oral non-steroidal antiandrogen (bicalutamide, $80 \mathrm{mg} /$ daily) was begun before or concomitant with the start of ADT.

Diagnosis during the clinical phase was performed by bone scintigraphy, magnetic resonance imaging (MRI), and computed tomography $(\mathrm{CT})$. The timing of PSA recurrence was defined as the day on which the PSA level increased by $\geq 25 \%$ and $\geq 2.0 \mathrm{ng} / \mathrm{mL}$ from the nadir level. If PSA did not decrease from the baseline, PSA recurrence was confirmed in the 12th week from the day on which treatment was started.

The primary end point was PSA-PFS, whereas the secondary end point was OS.

The chi-square test was used for comparison of the rates between the two groups and Wilcoxon's rank sum test was used for comparison of the median values between the two groups. Kaplan-Meier analysis was used to estimate the differences in time to events between the $\mathrm{CAB}$-antagonist group and the $\mathrm{CAB}$-agonist group using the log-rank test. Prognostic factors consisted of age at the time of diagnosis, bone metastasis, Gleason score (GS), and application of CAB-antagonist therapy, and multivariate analyses were performed with Cox's proportional hazard models. Statistical analyses were performed using SAS JMP, Version 13, and $P<0.05$ was taken to indicate statistical significance.

This study was approved by the Institutional Review Board of Saku Central Hospital.

\section{Results}

The study population consisted of 34 patients in the $\mathrm{CAB}$-antagonist group and 50 in the $\mathrm{CAB}$-agonist group. Their clinical characteristics and observation periods are shown in Table 1. Pathologically, there were 24 cases (71\%) in the CAB-antagonist group and $40(80 \%)$ in the $\mathrm{CAB}$-agonist group with $\mathrm{GS} \geq 8$. The difference between the two groups was not significant $(P=0.19)$. In the total population, Seventy patients $(83 \%)$ had primary tumor category $\geq$ T3, 57 patients (69\%) had metastatic Pca, 44 (54\%) had bone metastasis, and $46(56 \%)$ had lymph node metastasis. Thirty-two patients $(40 \%)$ had concurrent bone metastasis and lymph node metastasis, 11 (14\%) had bone metastasis alone, and 13 (17\%) had only lymph node metastasis. Among the cases with bone metastasis, $13(72 \%)$ in the CAB-antagonist group and $19(73 \%)$ in the CAB-agonist group were treated with denosumab or zoledronic acid, respectively; the difference between the two groups was not significant. Thirty-five (69\%) of 52 patients with PSA level $>100 \mathrm{ng} / \mathrm{mL}$ and nine (28\%) of 32 patients with PSA level $50-100 \mathrm{ng} / \mathrm{mL}$ had bone metastases in the present study. The number of bone metastatic Pca patients with PSA level $>100 \mathrm{ng} / \mathrm{mL}$ was significantly greater than that of patients with PSA level $50-100 \mathrm{ng} / \mathrm{mL}(P<0.01)$.

There were no significant differences between the two groups in terms of age at the time of diagnosis, bone metastasis, lymph node metastasis, GS, or pretreatment PSA level. The two groups were not mismatched with regard to patient characteristics, but there were differences in observation period between the groups. No 


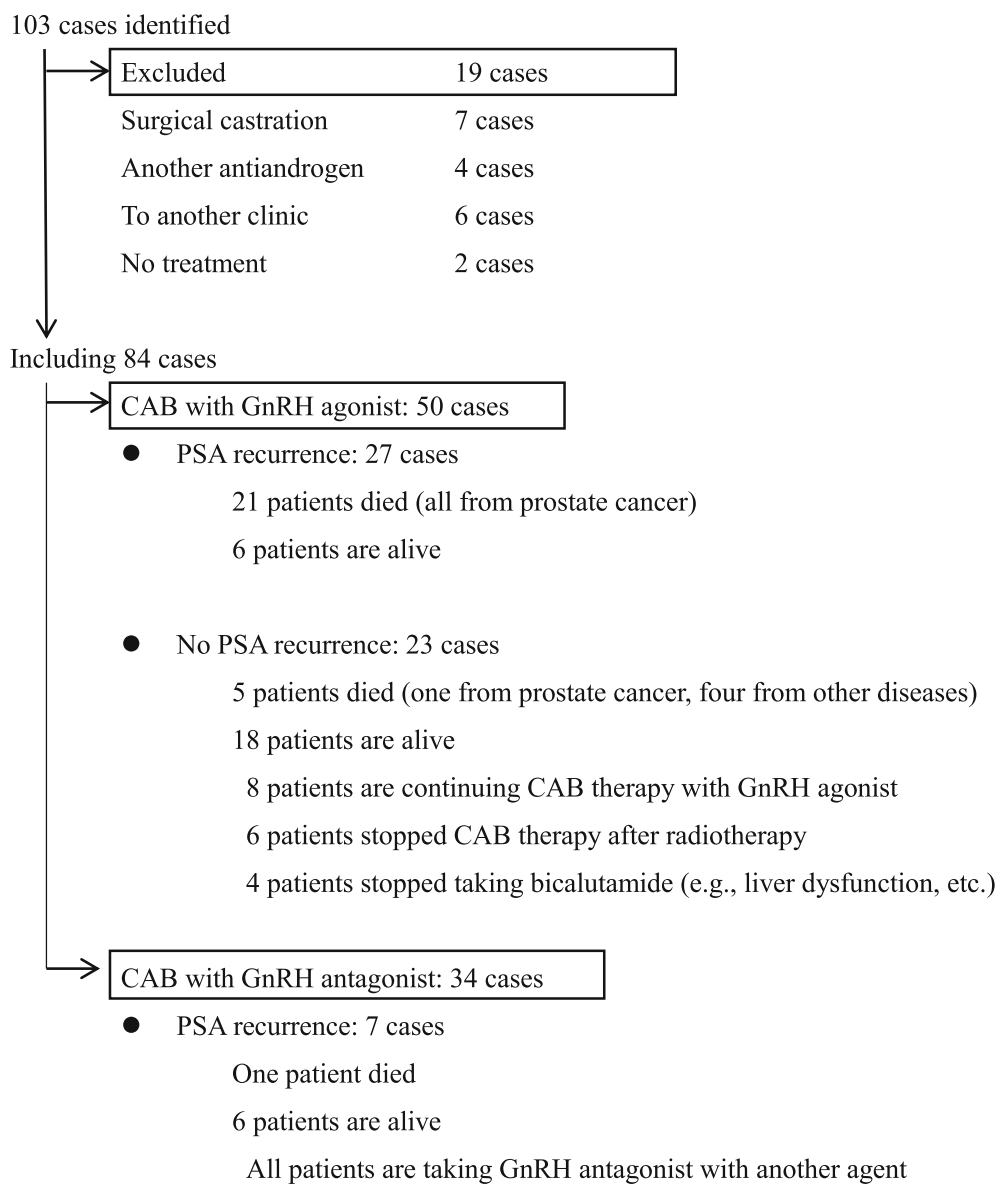

- No PSA recurrence: 27 cases

All patients are alive

16 patients are continuing $\mathrm{CAB}$ therapy with $\mathrm{GnRH}$ antagonist

6 patients stopped taking bicalutamide (e.g., liver dysfunction, etc.)

3 patients stopped undergoing $\mathrm{CAB}$ therapy after radiotherapy

2 patients went to another clinic

Fig. 1 Selection and outcome of patients pathologically diagnosed with pretreatment PSA level $\geq 50 \mathrm{ng} / \mathrm{mL}$

patients in either group suffered from cardiovascular disease during the observation period.

PSA recurrence within 1 year was observed in five patients (15\%) in the CAB-antagonist group, and one patient died from Pca during the observation period. PSA recurred within 1 year in 22 patients $(44 \%)$ in the CAB-agonist group. Twenty-one patients died from Pca among those patients with PSA recurrence in the CAB-agonist group during the observation period (Fig. 1). All patients with PSA recurrence had bone or lymph node metastasis at the time of diagnosis.

PSA-PFS (Fig. 2a) and OS (Fig. 2b) of patients with PSA level $\geq 50 \mathrm{ng} / \mathrm{mL}$ were significantly different between the two groups in the Kaplan-Meier estimate.
Among cases with bone metastasis, there were significant differences in PSA-PFS (Fig. 3a) and OS (Fig. 3b) between the two groups. Patients with PSA level $\geq 50 \mathrm{ng} /$ $\mathrm{mL}$ without metastasis between both groups showed no differences in PSA-PFS (Fig. 4a) or OS (Fig. 4b). Eight of 27 patients without metastasis received adjuvant radiation therapy, three patients were in the $\mathrm{CAB}$-antagonist group and five were in the $C A B$-agonist group.

The $C A B$-antagonist group with high volume disease, defined as more than six bone metastases (the extent of disease (EOD) grade 2-4), was associated with significantly greater improvement of PSA-PFS (Fig. 5b) in the Kaplan-Meier estimate compared to the CAB-agonist group $[9,10]$. The two groups with low volume disease, 
Table 1 Patient characteristics

\begin{tabular}{|c|c|c|c|c|}
\hline & & CAB with $\mathrm{GnRH}$ antagonist & CAB with GnRH agonist & \\
\hline & & $n=34$ & $n=50$ & $P$-value \\
\hline Median age at diagnosis years (range) & & $75(50-88)$ & $74(55-85)$ & $0.09+$ \\
\hline$\geq 75$ years old $(\%)$ & & $19(56)$ & $22(44)$ & $0.28 \neq$ \\
\hline Median pretreatment PSA level ng/mL (range) & & $176.4(51.5-5076)$ & $136.4(51.9-5827)$ & $0.82 \dagger$ \\
\hline \multirow[t]{5}{*}{ Pathological diagnosis } & Gleason score 6 & 1 & 2 & \multirow[t]{5}{*}{$0.78 \neq$} \\
\hline & Gleason score 7 & 9 & 8 & \\
\hline & Gleason score 8 & 11 & 21 & \\
\hline & Gleason score 9 & 11 & 16 & \\
\hline & Gleason score10 & 2 & 3 & \\
\hline No of Gleason score 8-10 (\%) & & $24(70)$ & $40(80)$ & $0.19 \neq$ \\
\hline \multirow[t]{4}{*}{ T category } & T2 & 4 & 9 & \multirow[t]{4}{*}{$0.60 \neq$} \\
\hline & T3 & 24 & 33 & \\
\hline & T4 & 6 & 7 & \\
\hline & Unknown & 0 & 1 & \\
\hline \multirow[t]{6}{*}{ Bone metastasis } & EODO & 16 & 22 & \multirow[t]{6}{*}{$0.72 \ddagger$} \\
\hline & EOD1 & 7 & 9 & \\
\hline & EOD2 & 8 & 10 & \\
\hline & EOD3 & 3 & 6 & \\
\hline & EOD4 & 0 & 1 & \\
\hline & Unknown & 0 & 2 & \\
\hline \multirow[t]{3}{*}{ Lymph node metastasis (\%) } & Positive & $21(62)$ & $25(50)$ & \multirow[t]{3}{*}{$0.58 \neq$} \\
\hline & Negative & $13(38)$ & $23(46)$ & \\
\hline & Unknown & 0 & 2 & \\
\hline \multirow[t]{2}{*}{ When to use bicalutamide } & Concurrently & 15 & 12 & \\
\hline & Before & 19 & 38 & \\
\hline Median observation period days (range) & & $761(212-1529)$ & $1141(175-3419)$ & $<0.01^{*}$ \\
\hline
\end{tabular}

†: Wilcoxon's rank sum test, $\neq$ : Chi-square test, *: Log-rank test

$C A B$ combined androgen blockade, EOD the extent of disease, GnRH gonadotropin-releasing hormone, PSA prostate-specific antigen EOD stratification

EOD grade 0 ; normal and benign bone disease

EOD grade 1 ; number of bone metastases $<6$

EOD grade 2; number of bone metastases $6-20$

EOD grade 3; number of bone metastases $>20$ but less than "super scan"

EOD grade 4; super scan

defined as less than six bone metastases (EOD grade 1), showed no differences in PSA-PFS (Fig. 5a). Median PSA levels during treatment in the two groups are shown in Fig. 6a. There was a significant difference in PSA elevation $>4 \mathrm{ng} / \mathrm{mL}$ after commencement of $\mathrm{CAB}$ therapy between the two groups (Fig. 6b). On multivariate analysis, $\mathrm{CAB}$-antagonist therapy was shown to be a significant prognostic factor for PSA-PFS (Table 2) in Pca patients with pretreatment PSA level $\geq 50 \mathrm{ng} / \mathrm{mL}$.

\section{Discussion}

ADT has become the primary treatment option in cases of advanced Pca since Huggins et al. first reported the clinical efficacy of orchiectomy in such patients [11].

CAB therapy to block adrenal gland-derived testosterone was first reported in 1979. There have since been a number of reports that $C A B$ therapy has a greater effect in improving survival rate than castration alone, but it has not been adopted as a standard therapy around the world $[12,13]$.

CAB therapy, in which a nonsteroidal antiandrogen is used along with GnRH agonist, has been used in 59\% of patients with advanced Pca in Japan. CAB therapy is increasingly used with increasing Gleason score and clinical stage $[14,15]$. In Japan, CAB therapy has been adopted as a standard treatment modality for advanced Pca. However, CAB-agonist therapy does not sufficiently improve prognosis in cases of bone metastatic Pca. Recently, next-generation $\mathrm{CAB}$ therapy with abiraterone 


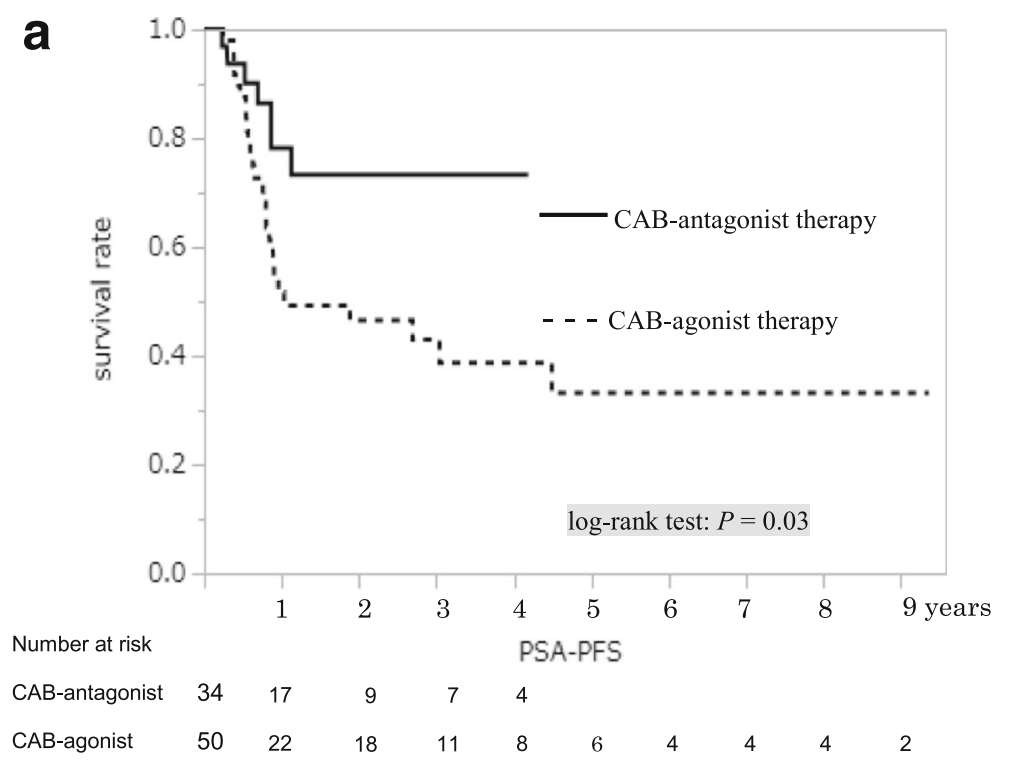

b

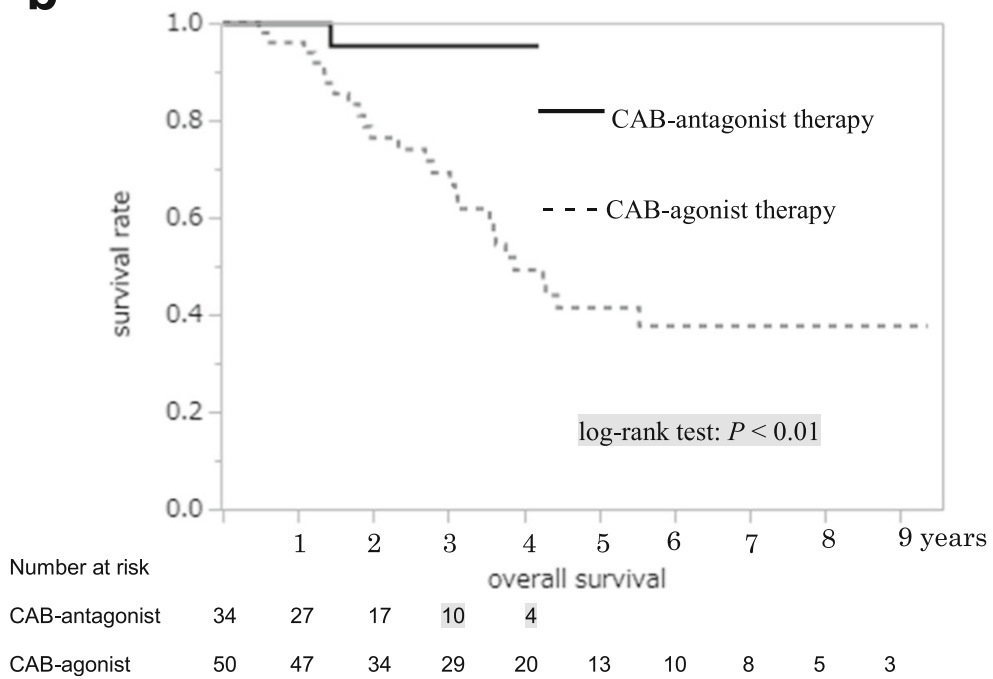

Fig. 2 Kaplan-Meier curves of prostate-specific antigen progression-free survival (PSA-PFS) (a) and overall survival (OS) (b) showed significantly better results in the group undergoing combined androgen blockade therapy with concurrent gonadotropin-releasing hormone antagonist (CAB-antagonist therapy) than the group undergoing combined androgen blockade therapy with concurrent gonadotropin-releasing hormone agonist (CAB-agonist therapy) among prostate cancer patients with pretreatment PSA level $\geq 50 \mathrm{ng} / \mathrm{mL}$

and ADT was shown to significantly prolong OS and progression-free survival in metastatic Pca and HSPC compared to ADT alone. GnRH agonists as ADT were used for most metastatic Pca patients in these studies [3, 4]. The present study examined therapeutic effects of CAB therapy with GnRH antagonist and GnRH agonist concurrently using the conventional antiandrogen, bicalutamide in Pca patients with PSA level $>50 \mathrm{ng} / \mathrm{mL}$.

GnRH antagonists competitively inhibit GnRH from the hypothalamus. These interactions result in suppression of luteinizing hormone ( $\mathrm{LH}$ ) and follicle-stimulating hormone (FSH) secretion from the pituitary gland. $\mathrm{GnRH}$ antagonists do not lead to a transient rise in testosterone (testosterone surge) as seen with $\mathrm{GnRH}$ agonists. After 1 month of treatment, 59\% of patients treated with the GnRH antagonist, degarelix, reached a PSA level of $\leq 4 \mathrm{ng} / \mathrm{mL}$, suggesting a faster pace of decrease in PSA level compared to patients treated with leuprorelin [6]. In the present study, the PSA level from baseline decreased rapidly in the two groups, however there was a significant difference in PSA elevation $>4 \mathrm{ng} / \mathrm{mL}$ after commencement of $\mathrm{CAB}$ therapy between the two groups. Metastatic Pca patients with PSA level $>4 \mathrm{ng} / \mathrm{mL}$ 

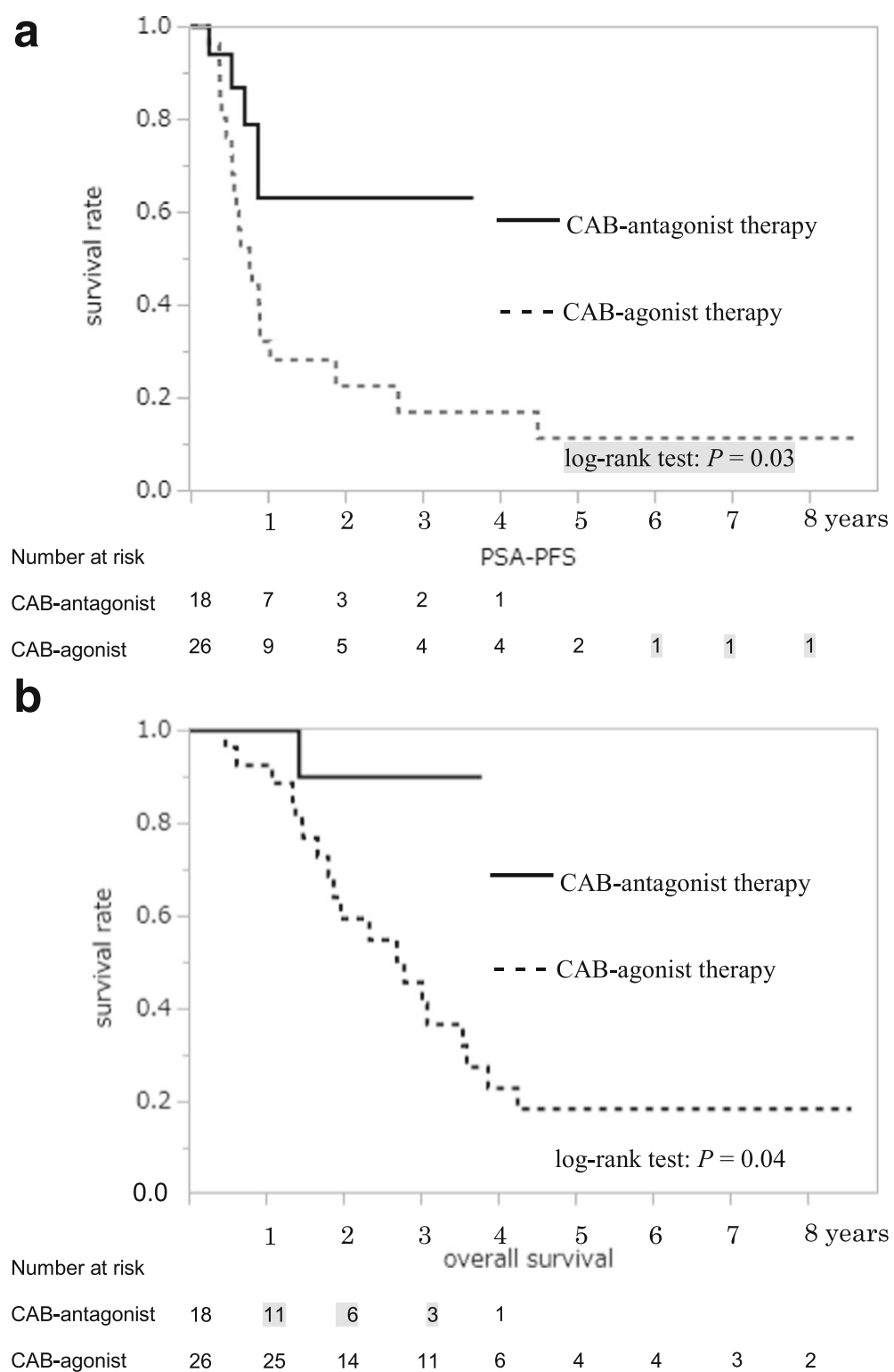

Fig. 3 Kaplan-Meier curves for prostate-specific antigen progression-free survival (PSA-PFS) (a) and overall survival (OS) (b) showed significantly better results in the group undergoing combined androgen blockade therapy with concurrent gonadotropin-releasing hormone antagonist (CAB-antagonist therapy, $n=18$ ) than the group undergoing combined androgen blockade therapy with concurrent gonadotropin-releasing hormone agonist (CAB-agonist therapy, $n=26$ ) among patients with bone metastatic prostate cancer

at 7 months after commencement of therapy could be early treatment failure and PSA levels rarely decreased further after 6 months [16]. PSA-PFS was associated with OS. [17]. PSA elevation $>4 \mathrm{ng} / \mathrm{ml}$ was clinically important to detect treatment failure at an early time point after commencement of primary $\mathrm{CAB}$ therapy. These findings indicated the efficacy of $\mathrm{CAB}$-antagonist therapy for metastatic Pca.

In metastatic Pca, PSA recurrence was reported 1824 months after the start of ADT. In the present study, PSA recurrence was observed at rates of 79 and $91 \%$ within 1 and 2 years, respectively. The PSA recurrence rate increased rapidly, particularly with $P S A \geq 50 \mathrm{ng} / \mathrm{mL}$ at the time of diagnosis. Particularly for clinical cases with pretreatment PSA $\geq 50 \mathrm{ng} / \mathrm{mL}$, the PSA recurrence rate within 1 year decreased to $29 \%$ for the degarelix group, in comparison to $40 \%$ for the leuprorelin group [6]. In the present study, the PSA recurrence rates within 1 year were $15 \%$ for the $C A B$-antagonist group and $44 \%$ for the $\mathrm{CAB}$-agonist group. Thus, $\mathrm{CAB}$-antagonist group showed a significantly reduced PSA recurrence rate, suggesting that the PSA recurrence rate using 


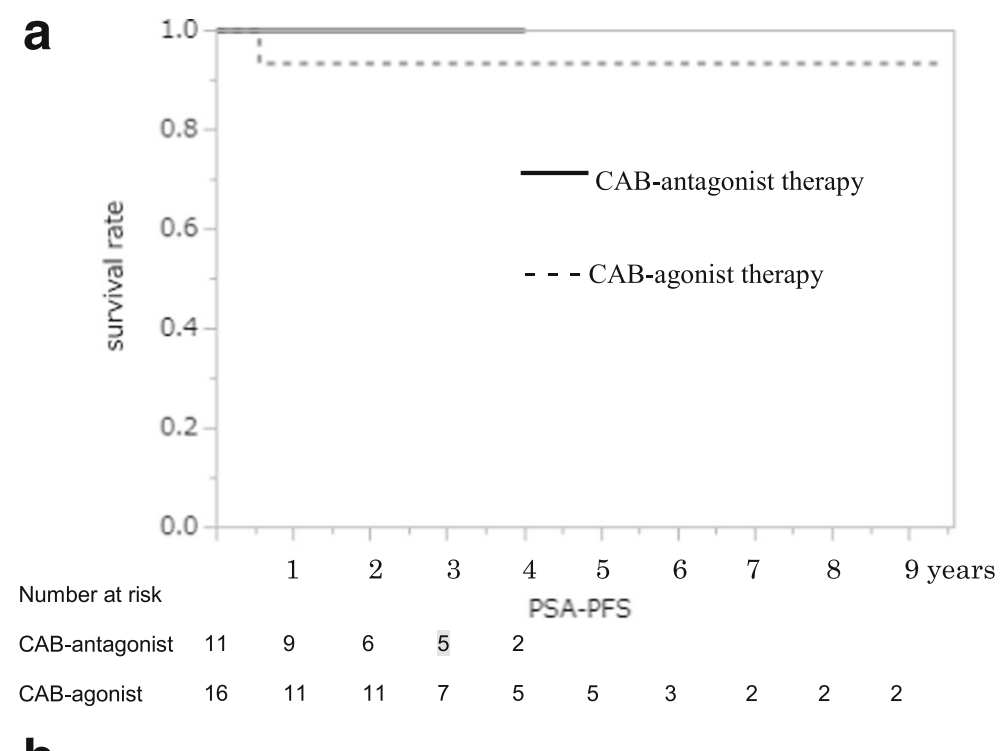

b

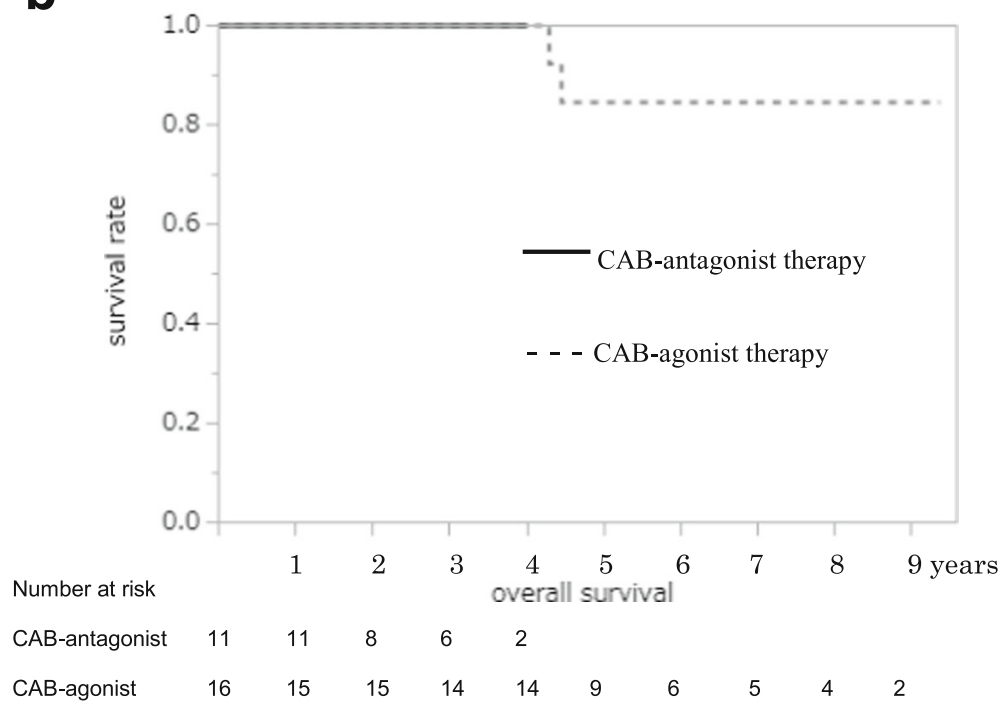

Fig. 4 Kaplan-Meier curves for prostate-specific antigen progression-free survival (PSA-PFS) (a) and overall survival (OS) (b) showed no difference between the group undergoing combined androgen blockade therapy with concurrent gonadotropin-releasing hormone antagonist (CAB-antagonist therapy, $n=11$ ) and the group undergoing combined androgen blockade therapy with concurrent gonadotropin-releasing hormone agonist (CAB-agonist therapy, $n=16)$ in patients without metastatic prostate cancer

CAB-antagonist may be lower than that with $G n R H$ antagonist alone.

The results of the present study indicated that CAB-antagonist therapy improved PSA-PFS to a significantly greater extent than CAB-agonist therapy. This suggests that $\mathrm{CAB}$ therapy using both $\mathrm{GnRH}$ antagonist and nonsteroidal antiandrogen agent may prevent PSA recurrence and further improve PSA-PFS. In advanced Pca, the retention of PSA at a low level by initial-phase endocrine therapy improves the prognosis [16]. It was reported that GnRH antagonist significantly prolonged PSA-PFS compared to treatment with GnRH agonist [18]. In cases of metastatic Pca, CAB-agonist therapy significantly improved OS in cases with lymph node metastasis. In contrast, $\mathrm{CAB}$-agonist therapy did not improve OS in cases with bone metastasis. To improve the prognosis of advanced Pca, it is necessary to improve the prognosis of bone metastatic Pca. Our findings indicated that $\mathrm{CAB}$-antagonist therapy prolonged PSA-PFS to a greater extent than CAB-agonist therapy in KaplanMeier estimate. The greater improvement of PSA-PFS by $\mathrm{CAB}$-antagonist therapy may be clinically significant for metastatic Pca.

Currently abiraterone or docetaxel with ADT have been reported to be beneficial in cases of high-volume disease stratified according to visceral metastasis or the 

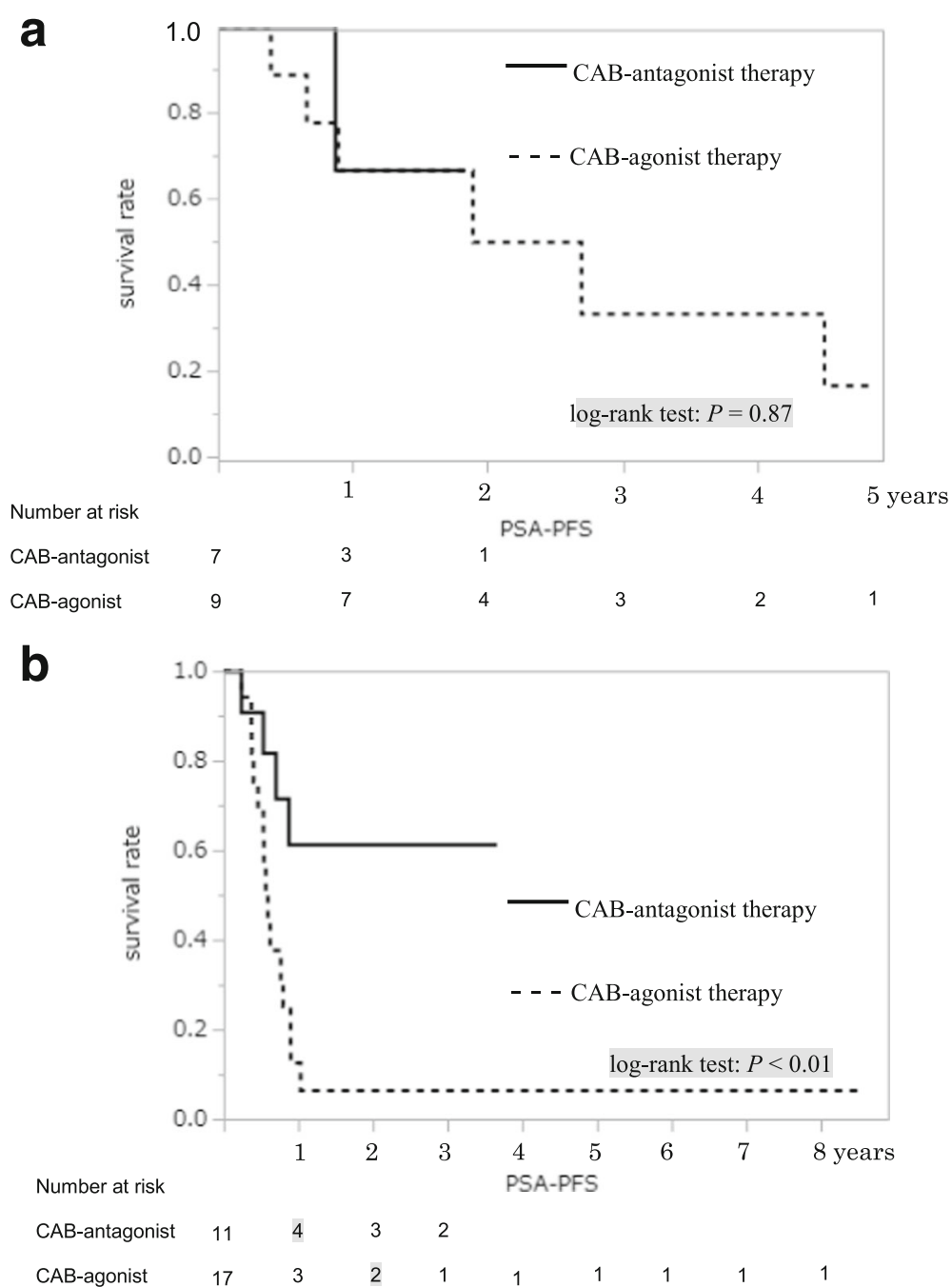

Fig. 5 Kaplan-Meier curves for prostate-specific antigen progression-free survival (PSA-PFS) showed significantly better results in the group undergoing combined androgen blockade therapy with concurrent gonadotropin-releasing hormone antagonist (CAB-antagonist therapy, $n=11$ ) than the group undergoing combined androgen blockade therapy with concurrent gonadotropin-releasing hormone agonist (CAB-agonist therapy, $n=17$ ) in prostate cancer patients with more than six bone metastases $(\mathbf{b})$. There were no differences between the two groups in prostate cancer patients with less than six bone metastases (a)

number of bone metastases $[3,4,10]$. In the present study, CAB-antagonist therapy with more than six bone metastases (EOD grade 2-4) was associated with greater improvement in PSA-PFS than CAB-agonist therapy. Multivariate analysis indicated that $\mathrm{CAB}$-antagonist therapy was a possible prognostic factor for PSA-PFS.

Although the reasons for the above observations are not yet clear, there are a number of possible underlying mechanisms. One mechanism may involve the lack of testosterone surge when degarelix is used, as the flare phenomenon defined as aggravation of Pca is stimulated by the testosterone surge, resulting in death in some cases [19]. In cases with advanced and metastatic Pca, including those with pretreatment PSA $\geq 50 \mathrm{ng} / \mathrm{mL}$, antiandrogen therapy is used before $\mathrm{GnRH}$ agonist to prevent the flare phenomenon. However, it has been reported that the testosterone surge occurs in $74 \%$ of patients even with antiandrogen administration [20]. In cases with pretreatment PSA $\geq 50 \mathrm{ng} / \mathrm{mL}$, PSA-PFS showed a more significant improvement in the group treated with degarelix alone than in the group given $\mathrm{GnRH}$ agonist, in which antiandrogens were administered to prevent the flare phenomenon [8]. Therefore, degarelix, which is not associated with a testosterone surge, may improve the prognosis of metastatic Pca.

Another mechanism involves the administration of degarelix to inhibit FSH secretion. In recent years, attention has focused on the influence of FSH in Pca, which is as significant as that of testosterone [21]. Degarelix was reported to be capable of maintaining FSH at a low level during the period of treatment [20]. 

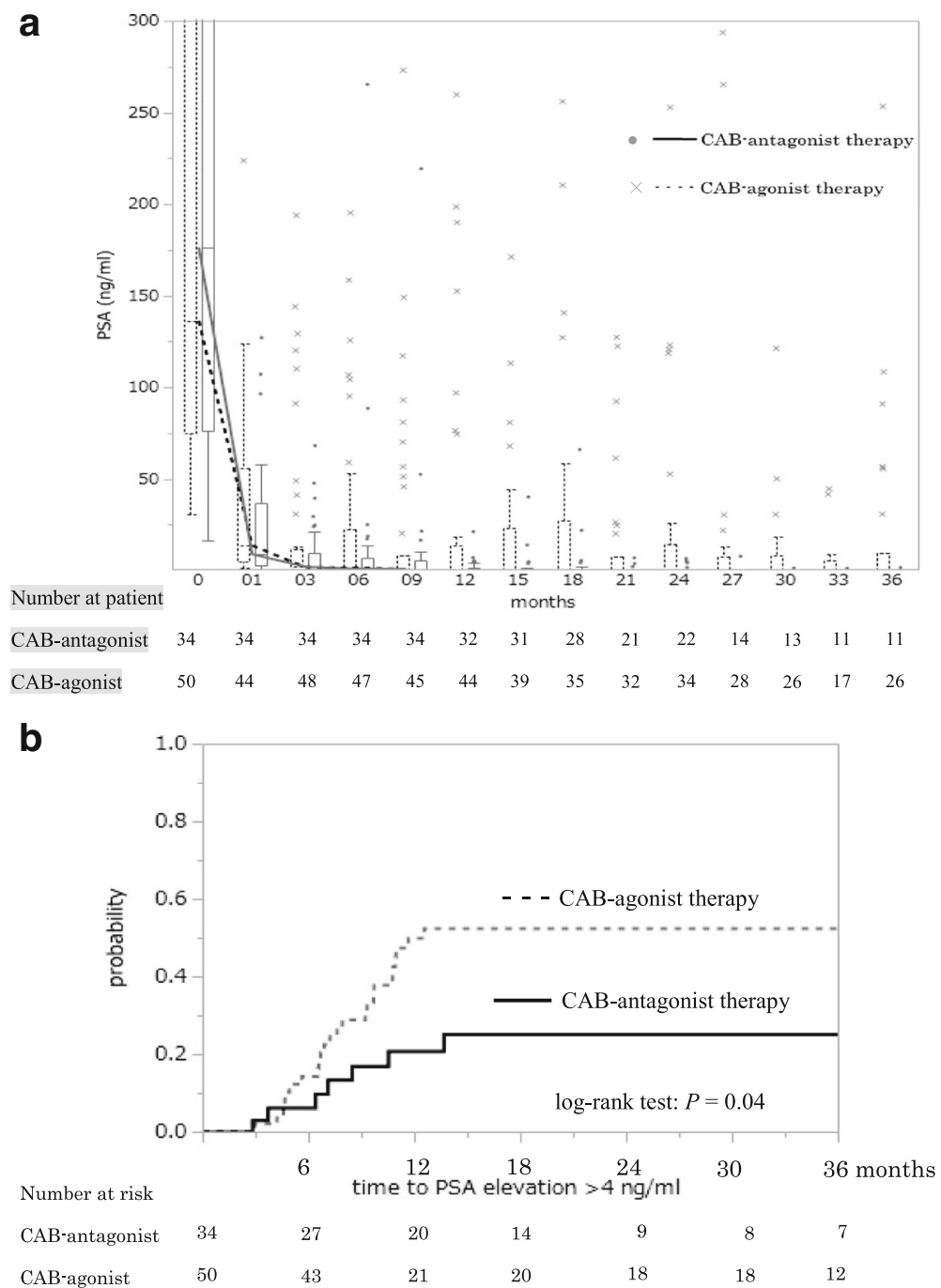

Fig. 6 a Prostate-specific antigen (PSA) level during treatment in the two groupsThe black line shows the median PSA level in combined androgen blockade (CAB) therapy with concurrent gonadotropin-releasing hormone (GnRH) antagonist (CAB-antagonist therapy) and the black-dotted line shows the median PSA level in CAB therapy with concurrent GnRH agonist (CAB-agonist therapy). The box plot indicates upper whisker (+ 1.5 interquartile range), upper quartile, median, lower quartile, and lower whisker (- 1.5 interquartile range), respectively, with outlier marks. b The probability of PSA elevation $>4 \mathrm{ng} / \mathrm{mL}$ was significantly lower in CAB-antagonist therapy than CAB-agonist therapy in prostate cancer patients with PSA level $>50 \mathrm{ng} / \mathrm{ml}$

Table 2 Multivariate analysis for PSA-PFS

\begin{tabular}{|c|c|c|c|c|c|c|}
\hline & \multicolumn{3}{|c|}{ Univariate analysis } & \multicolumn{3}{|c|}{ Multivariate analysis } \\
\hline & $\mathrm{HR}$ & $95 \% \mathrm{Cl}$ & $P$-value & $\mathrm{HR}$ & $95 \% \mathrm{Cl}$ & $P$-value \\
\hline$\geq 75$ years old at diagnosis & 1.09 & $0.55-2.16$ & 0.79 & 1.17 & $0.59-2.35$ & 0.65 \\
\hline CAB therapy with GnRH antagonist & 0.40 & $0.16-0.87$ & 0.02 & 0.41 & $0.16-0.90$ & 0.03 \\
\hline Bone metastasis positive & 4.12 & $1.93-9.79$ & $<0.01$ & 3.60 & $1.66-8.74$ & $<0.01$ \\
\hline Gleason score $\geq 8$ & 3.38 & $1.21-14.07$ & 0.02 & 1.94 & $0.66-8.34$ & 0.25 \\
\hline
\end{tabular}


FSH is considered important for bone metabolism as it regulates the control of bone resorption and the formation of osteoblasts and osteoclasts. Degarelix maintains alkaline phosphatase (ALP), a marker of bone metastasis, at a low level during the period of treatment. ALP level rose in the GnRH agonist group 10 months after commencement of treatment [7]. The delayed ALP rise after commencement of $\mathrm{GnRH}$ agonist administration may represent a therapeutic failure for advanced Pca. This phenomenon suggests that the impacts of the testosterone surge and the transient rise in FSH in the initial phase of GnRH agonist treatment remain intact even after inhibition of testosterone. The lack of a delayed increase in ALP after commencement of degarelix treatment suggests that the aggravation of bone metastasis is inhibited. FSH receptor expression has been confirmed in cases of castration-resistant prostate cancer (CRPC). Lower FSH level is associated with longer period of progression from HSPC to CRPC [22]. The observations with degarelix treatment suggested that delayed transition to CRPC may be related to improved prognosis of bone metastatic Pca.

There have been few reports regarding the effectiveness of $\mathrm{CAB}$-antagonist therapy as the initial-phase endocrine therapy in metastatic Pca. The results of the present study suggest that $\mathrm{CAB}$-antagonist therapy may reduce PSA recurrence and prolong PSA-PFS in bone metastatic Pca. Thus, the present study suggested that CAB-antagonist therapy may improve the prognosis of bone metastatic Pca with EOD grade 2-4.

The survival of Pca patients is related to several risk factors, including the extent of the tumor, pathological grade, patient's age, and pretreatment PSA level [23-26]. Patients with lymph node metastases were reported to have better outcome than those with bone metastases [26]. Pretreatment PSA levels could be associated with bone metastases in the present study. Prognostic factors consisting of patient's age at the time of diagnosis, bone metastasis, GS, and application of CAB-antagonist therapy would be suitable for the present multivariate analysis of PSA-PFS. CAB-antagonist therapy was found to be a possible prognostic factor for PSA-PFS; however, the frequency of PSA recurrence and number of deaths were so small that there may have been confounding factors or bias that were not addressed in the present study.

The limitations of the present study include the small number of the two groups, the study was performed in a single institute, its retrospective nature, concern regarding matching between the two groups in terms of the patient population with Gleason score 8-10. Risk of bias resulting from differences in number at risk in each year on the Kaplan-Meier curve for PSA-PFS must be taken into consideration, because the observation periods between the two groups were significantly different and would represent an important source of bias. Therefore, the present study may not have allowed adequate assessment of the effects of CAB-antagonist therapy for bone metastatic prostate cancer. Despite these limitations, our findings could help to improve the prognosis of bone metastatic prostate cancer patients. Further large-scale prospective studies with well-matched groups of patients are required to confirm our findings.

\section{Conclusions}

In cases of bone metastatic Pca with pretreatment PSA level $\geq 50 \mathrm{ng} / \mathrm{mL}, \mathrm{CAB}$-antagonist therapy as the primary ADT could be associated with greater prolongation of PSA-PFS than CAB-agonist therapy. CAB-antagonist therapy may be a useful therapeutically option for treatment of bone metastatic Pca patients with EOD grade 2-4.

\section{Abbreviations}

ADT: Androgen deprivation therapy; ALP: Alkaline phosphatase;

CAB: Combined androgen blockade; CAB-agonist: Combined androgen blockade with concurrent use of gonadotropin-releasing hormone agonist; CAB-antagonist: Combined androgen blockade with concurrent use of gonadotropin-releasing hormone antagonist; Cl: Confidence interval; CRPC: Castration-resistant prostate cancer; EOD: The extent of disease; FSH: Follicle-stimulating hormone; GnRH: Gonadotropin-releasing hormone; GS: Gleason score; HR: Hazard ratio; HSPC: Hormone-sensitive prostate cancer; LH: Luteinizing hormone; OS: Overall survival; PFS: Progression-free survival; PSA: Prostate-specific antigen; PSA-PFS: Prostate-specific antigen progression-free survival

\section{Acknowledgements \\ Thanks are due to Mr. Shin-Ichirou Yoshimoto for his linguistic advice.}

\section{Availability of data and materials}

The datasets analyzed during the present study are available from the corresponding author on reasonable request. Individual patient data cannot be made available.

\section{Authors' contributions}

TK conceived of the study and wrote the draft. SS revised the draft. TK and SS contributed to data collection and analysis. Both authors read and approved the final manuscript.

\section{Authors' information \\ TK and SS are urologists.}

\section{Ethics approval and consent to participate}

The present study was approved by the Institutional Review Board (IRB) of Saku Central Hospital (Reference number: R201510-04). Consent was obtained from all participants included in the study through the opt-out method in accordance with the national regulations and the ethical guidelines for clinical studies in Japan. The IRB waived the requirement for written informed consent due to the retrospective nature of the present analysis.

\section{Competing interests}

The authors declare that they have no competing interests.

\section{Publisher's Note}

Springer Nature remains neutral with regard to jurisdictional claims in published maps and institutional affiliations. 
Received: 1 October 2017 Accepted: 21 May 2018

Published online: 31 May 2018

\section{References}

1. Fujimoto H, Nakanishi H, Miki T, Kubota Y, Takahashi S, Suzuki K, et al. Oncological outcomes of the Pca patients registered in 2004: report from the Cancer registration committee of the JUA. Int J Urol. 2011;18:876-81.

2. Cooperberg MR, Hinotsu S, Namiki M, Carroll PR, Akaza H. Trans-Pacific variation in outcomes for men treated with primary androgen-deprivation therapy (ADT) for prostate cancer. BJU Int. 2016;117:102-9.

3. Fizazi K, Tran N, Fein L, Matsubara N, Rodriguez-Antolin A, Alekseev BY, et al. Abiraterone plus prednisone in metastatic, castration-sensitive prostate cancer. N Engl J Med. 2017:377:352-60.

4. James ND, de Bono JS, Spears MR, Clarke NW, Mason MD, Dearnaley $D P$, et al. Abiraterone for prostate cancer not previously treated with hormone therapy. N Engl J Med. 2017;377:338-51.

5. Wiebe E, Rodrigues G, Lock M, D'Souza D, Stitt L. Outcome analysis of prostate cancer patients with pretreatment PSA greater than $50 \mathrm{ng} / \mathrm{ml}$. Can J Urol. 2008;15:4078-83.

6. Tombal B, Miller K, Boccon-Gibod L, Schröder F, Shore N, Crawford ED, et al Additional analysis of the secondary end point of biochemical recurrence rate in a phase 3 trial (CS21) comparing degarelix 80 mg versus leuprolide in prostate cancer patients segmented by baseline characteristics. Eur Urol. 2010;57:836-42.

7. Schröder FH, Tombal B, Miller K, Boccon-Gibod L, Shore ND, Crawford ED, et al. Changes in alkaline phosphatase levels in patients with prostate cancer receiving degarelix or leuprolide: results from a 12-month, comparative, phase III study. BJU Int. 2010;106:182-7.

8. Iversen $\mathrm{P}$, Damber JE, Malmberg A, Persson BE, Klotz L. Degarelix monotherapy compared with luteinizing hormone-releasing hormone $(\mathrm{GnRH})$ agonists plus anti-androgen flare protection in advanced prostate cancer: an analysis of two randomized controlled trials. Ther Adv Urol. 2016:8:75-82.

9. Soloway MS, Hardeman SW, Hickey D, Raymond J, Todd B, Soloway S, et al. Stratification of patients with metastatic prostate cancer based on extent of disease on initial bone scan. Cancer. 1988;61:195-202.

10. Sweeney CJ, Chen YH, Carducci M, Liu G, Jarrard DF, Eisenberger M, et al. Chemohormonal therapy in metastatic hormone-sensitive prostate cancer. N Engl J Med. 2015;373:737-46.

11. Huggins C, Hodge CV. Studies on prostate cancer. I. The effect of castration, of estrogen and of androgen injection on serum phosphatases in metastatic carcinoma of prostate. Cancer Res. 1941;1:293-7.

12. Klotz $L$, Schellhammer $P$, Carroll $K$. A reassessment of the role of combined androgen blockade for advanced prostate cancer. BJU Int. 2004;93:1177-82.

13. Chen $X Q$, Huang $Y$, Li $X$, Zhang $P$, Huang $R$, Xia J, et al. Efficacy of maximal androgen blockade versus castration alone in the treatment of advanced prostate cancer: a retrospective clinical experience from a Chinese medical centre. Asian J Androl. 2010;12:718-27.

14. Hinotsu S, Akaza H, Usami M, Ogawa O, Kagawa S, Kitamura T, et al. Current status of endocrine therapy for prostate cancer in Japan-analysis of primary androgen deprivation therapy on the basis of data collected by J-CaP. Jpn Clin Oncol. 2007;37:775-81

15. Akaza H, Hinotsu S, Usami M, Arai Y, Kanetake H, Naito S, et al. Combined androgen blockade with Bicalutamide for advanced prostate cancer. Longterm follow-up of a phase 3, double-blind, randomized study for survival. Cancer. 2009:115:3437-45.

16. Hussain M, Tangen CM, Higano C, Schelhammer PF, Faulkner J, Crawford $E D$, et al. Absolute prostate-specific antigen value after androgen deprivation is a strong independent predictor of survival in new metastatic prostate Cancer: data from southwest oncology group trial 9346 (INT-0162). J Clin Oncol. 2006:24:3984-90.

17. Halabi S, Vogelzang NJ, Ou SS, Owzar K, Archer L, Small EJ. Progression-free survival as predictor of overall survival in men with castrate-resistant prostate cancer. J Clin Oncol. 2009;27:2766-71

18. Klotz L, Miller K, Crawford ED, Shore N, Tombal B, Karup C, et al. Disease control outcomes from analysis of pooled individual patient data from five comparative randomized clinical trials of degarelix versus luteinizing hormone-releasing hormone agonists. Eur Urol. 2014;66:1101-8.

19. Thompson IM. Flare associated with GnRH-agonist therapy. Rev Urol. 2014; 3(Suppl 3):10-4.
20. Klotz L, Boccon-Gibod L, Shore ND, Andreou C, Persson BE, Cantor P, et al The efficacy and safety of degarelix: a 12-month, comparative, randomized, open-label, parallel-group phaselll study in patients with prostate cancer. BJU Int. 2014;102:1531-8.

21. Porter AT, Ben-Josef E, F.A.C.R.O. Humoral mechanisms in prostate cancer: a role for FSH. Urol Oncol. 2001:6:131-8.

22. Hoare D, Skinner TAA, Black A, Robert Siemens DR. Serum follicle-stimulating hormone levels predict time to development of castration-resistant prostate cancer. Can Urol Assoc J. 2015;9:122-7.

23. Akaza H, Hinotsu S, Usami M, Ogawa O, Kitamura T, Suzuki K, et al. Evaluation of primary androgen deprivation therapy in prostate cancer patients using the J-CAPRA risk score. Prostate Int. 2013;1:81-8.

24. Chodak GW, Thisted RA, Gerber GS, Johansson JE, Adolfsson J, Jones GW, et al. Results of conservative management of clinically localized prostate cancer. N Engl J Med. 1994;330:242-8.

25. Kitagawa Y, Ueno S, Izumi K, Kadono Y, Mizokami A, Hinotsu S, et al. Clinical outcomes and nadir prostate-specific antigen (PSA) according to initial PSA levels in primary androgen deprivation therapy for metastatic prostate cancer. World J Urol. 2016:34:319-27.

26. Halabi S, Kelly WK, Ma H, Zhou H, Solomon NC, Fizazi K, et al. Meta-analysis evaluating the impact of site of metastasis on overall survival in men with castration-resistant prostate cancer. J Clin Oncol. 2016:34:1652-9.

\section{Ready to submit your research? Choose BMC and benefit from:}

- fast, convenient online submission

- thorough peer review by experienced researchers in your field

- rapid publication on acceptance

- support for research data, including large and complex data types

- gold Open Access which fosters wider collaboration and increased citations

- maximum visibility for your research: over $100 \mathrm{M}$ website views per year

At BMC, research is always in progress.

Learn more biomedcentral.com/submissions 